\title{
NUMERICAL AND ASYMPTOTIC ANALYSIS OF IGNITION PROCESSES
}

\author{
C. Treviño ${ }^{1}$ and $A$. Liñán \\ E.T.S.I. Aeronánticos, UPM \\ Plaza del Cardenal Cisneros 3, 28040 Madrid, Spain
}

\begin{abstract}
In this paper the transient process leading to ignition of a combustible mixture of lean hydrogen/air is studied using both Computational Singular Perturbation (CSP) techniques as well as asymptotic methods that allow us to deduce the most important regimes in the process as well as the characteristic times and the appropriate reduced kinetic mechanism involved. The CSP technique developed by Lam and co-workers has been used to follow closely the temperature and species concentration evolution with time up to the ignition event. For lean mixtures, the most important intermediate species is the atomic oxygen; the other radicals follow the quasi-steady state behavior. A closed form solution is then obtained for the ignition delay time, which compares very well with the numerical solution with full kinetics.
\end{abstract}

\section{Introduction}

To obtain of reduced kinetic schemes for processes with complex chemical kinetics is very attractive for several reasons. It reduces computer time and can be used to study more complex fluid mechanical problems as turbulent combustion with realistic kinetics. The simplest case is the ignition process of hydrogen/air mixtures where the detailed reaction mechanism is very well known (Baulch et al., 1972; Warnatz, 1984; and Dixon-Lewis et al., 1977). Several analyses have been published regarding the ignition of $\mathrm{H}_{2} / \mathrm{O}_{2}$ mixtures (Brokaw, 1965; Gardiner et al., 1981; Kailasaneth et al., 1982; Wiriyawit and Dabora, 1984; and Maas and Warnatz, 1989). The Zeroth dimensional analysis had been found to be enough to describe the ignition phenomena. Recently, efforts have been conducted in order to deduce a reduced kinetic mechanism that globally contains

\footnotetext{
${ }^{1}$ Currently, Facultad de Ciencias, UNAM, Mexico
} 
the essential features of the studied process (Peters, 1985). The procedure to obtain the reduced mechanism has been improved by the CSP (Computational Singular Perturbation) technique developed by Lam and Goussis (1989). Here, the chemical reactions are reordered in reaction groups associated to the same order of magnitude of the characteristic times. These reaction groups can be active, dead or dormant depending on the relation of their characteristic times to the actual relevant characteristic time of the studied process. The dead groups are related to fast chemical reactions from which the appropriate quasi-steady and partial equilibrium assumptions can be derived. The dormant groups are related to slow chemical reactions playing no role at that moment. From the active and dead groups the global mechanism can be obtained. Recently, Treviño (1990) studied the zeroth-dimensional ignition of $\mathrm{H}_{2} / \mathrm{O}_{2}$ mixtures in an isochoric adiabatic reactor. The reduced kinetic mechanism has been obtained after solving the evolution equations. Three different regimes were identified for the ignition process, depending on the initial temperature and pressure. For initial temperatures larger than the critical temperature (temperature that makes reaction rates of the chain branching reaction $\mathrm{H}+\mathrm{O}_{2} \rightarrow \mathrm{OH}+\mathrm{O}$ and the chain terminating reaction $\mathrm{H}+\mathrm{O}_{2}+\mathrm{M} \rightarrow \mathrm{HO}_{2}+\mathrm{M}$ equal in magnitude), the ignition can be described as a typical chain branching explosion with no heat release in a first approximation. As the temperature decreases to values close to the critical temperature, the heat release has to be retained in order to improve the ignition time. As the temperature decreases further, the chain branching reaction loses in importance and the intermediate species evolution control the process. A thermal runaway is produced in this regime characterizing the ignition process at low initial temperatures. In all three regimes, an analytical expression has been obtained for the ignition delay time. In the reduced kinetic mechanism for the high temperature regime, where the ignition process consumes $50 \%$ more fuel as given by stoichiometry, it is assumed that the rate limiting chemical reaction is $\mathrm{H}+\mathrm{O}_{2} \rightarrow \mathrm{OH}+\mathrm{O}$. This is true for stoichiometric and rich mixtures where abundant $\mathrm{H}_{2}$ exists. In this case all $\mathrm{H}_{2}$ consuming shuffle reactions are very fast. However, this reduced kinetic scheme is not valid for lean mixtures as found for example in the ignition of hydrogen in mixing layers in supersonic combustion engines, where the air temperature is much larger than that of the fuel.

The main objective of the present study is to deduce the relevant 
reduced kinetic mechanism valid for the high temperature ignition of lean $\mathrm{H}_{2}$ /air mixtures, using the CSP technique in order to obtain analytical expressions for the ignition delay time, using asymptotic methods.

\section{Governing Equations}

The zero-dimensional reacting governing equations of an homogeneous hydrogen/oxygen mixture in an adiabatic reactor are given by

$$
\begin{gathered}
\rho_{0} c_{p} d T / d t-d p / d t+\sum_{i=1}^{N} \dot{C}_{i} h_{i} M_{i}=0 \\
d C_{i}^{\prime} / d t=\dot{C}_{i}, i=1, N
\end{gathered}
$$

where $\rho_{0}$ corresponds to the mixture density assumed to be constant; $c_{p}$ is the specific heat at constant pressure; $T$ is the mixture temperature; $t$ corresponds to the time; $p$ is the pressure; $C_{i}$ corresponds to the molar concentration ( $\mathrm{mol} /$ volume) of the specie $i ; h_{i}$ is the specific enthalpy of species $i ; M_{i}$ is the molecular mass of species $i$. $N$ corresponds to the total number of species taking part in the ignition process. The mixture density is related to the species molar concentrations by

$$
\rho_{0}=\sum_{i=1}^{N} C_{i} M_{i}=\text { constant. }
$$

Assuming an ideal gas mixture, the state equation is given as

$$
p=R T \sum_{i=1}^{N} C_{i}
$$

where $R$ is the universal gas constant, $R=8.314 \mathrm{KJ} /(\mathrm{mol} \mathrm{K})$. From Eqs. (1) and (4), the energy equation (1) transforms to

$$
\rho_{0} c_{v} d T / d t+\sum_{i=1}^{N} \dot{C}_{i}\left(h_{i} M_{i}-R T\right)=0
$$

where $c_{v}$ corresponds to the specific heat at constant volume. The species production rate, $\dot{C}_{i}$ is given by

$$
\dot{C}_{i}=\sum_{j=1}^{M} K_{j}(T) \nu_{i j}^{\prime} \Pi_{k=1}^{N} C_{k}^{\nu_{k j}}, \text { with } K_{j}(T)=A_{j} T^{n_{j}} \exp \left(-E_{j} / R T\right)
$$


Here, $M$ corresponds to the total number of elementary chemical reactions; $v_{i j}^{\prime}$ and $v_{i j}$ corresponds to the stoichiometric coefficients of the species $i$ in the chemical reaction $j$, as product and as reactant, respectively. The constants $A_{j}, n_{j}$ and $E_{j}$ are given in Table 1 for all chemical reactions considered.

The solution of the governing equations (2) and (5), with the corresponding initial conditions,

$$
T=T_{0} \text { and } C_{i}=C_{i 0} \text { at } t=0,
$$

is obtained using conventional codes for stiff differential equations (DGEAR). This numerical code is driven by a CSP routine, built parallel to the main program. The procedure employed in order to obtain the reduced kinetic mechanism is by dropping out that reactions with a participation index (Lam and Coussis, 1989) lower than a critical value in the whole event leading to the ignition of the mixture. This critical value is the maximum value obtained when no appreciable change in the ignition time results after dropping these chemical reactions. The resulting set of chemical reactions can be reduced after the introduction of steady-state behavior of several species. In the present study 38 elementary chemical reactions are employed as the detailed kinetic mechanism as in Maas and Warnatz (1989).

\section{Asymptotic Analysis}

The ignition process of hydrogen with oxygen changes dramatically depending on the initial gas temperature. A critical temperature is obtained from the competition between the chain branching reaction (1) and the chain braking reaction (9). This crossover temperature is denoted by $T_{c}$. From the CSP data, the following elementary reactions are important for high initial temperatures and lean mixtures. At the beginning (no radicals present), reaction 14

$$
\mathrm{H}_{2}+\mathrm{O}_{2} \rightarrow \mathrm{HO}_{2}+\mathrm{H}
$$

is the important initiation step. Once trace amounts of radicals are present, this reaction has no more influence on the process in this high temperature limit. From this point up to the end, the three forward shuffe reactions are very important and have to be retained in the ignition process. These reactions are:

$$
\mathrm{H}+\mathrm{O}_{2} \rightarrow \mathrm{OH}+\mathrm{O}
$$




$$
\mathrm{H}_{2}+\mathrm{O} \rightarrow \mathrm{OH}+\mathrm{H}
$$

$$
\mathrm{H}_{2}+\mathrm{OH} \rightarrow \mathrm{H}_{2} \mathrm{O}+\mathrm{H} \text {. }
$$

Due to the fact that $\mathrm{H}_{2}$ is consumed rapidly in the ignition process of lean mixtures, reaction (7) becomes the most important $O H$ consumer reaction

$$
\mathrm{OH}+\mathrm{OH} \rightarrow \mathrm{H}_{2} \mathrm{O}+\mathrm{O}
$$

$\mathrm{HO}_{2}$ is produced mainly through reaction (9), whose rate is very slow compared with the other reactions for high initial temperatures

$$
\mathrm{H}+\mathrm{O}_{2}+\mathrm{M} \rightarrow \mathrm{HO}_{2}+\mathrm{M}
$$

The $\mathrm{HO}_{2}$ is being consumed mainly by reactions (15) and (19)

$$
\begin{gathered}
\mathrm{HO}_{2}+\mathrm{OH} \rightarrow \mathrm{H}_{2} \mathrm{O}+\mathrm{O}_{2} \\
\mathrm{HO}_{2}+\mathrm{O} \rightarrow \mathrm{OH}+\mathrm{O}_{2} .
\end{gathered}
$$

For very lean mixtures, reactions (3) and (5) are not very fast due to the low concentration of $H_{2}$ and become the rate limiting reactions in the ignition process. Reaction (1) now is very fast and makes the hydrogen atom to behave in quasi steady-state. A second run of the computer program with only these reactions $(14,1,3,5,8$, $9,15,19)$, reproduces the same ignition delay time as with all the reactions included. The backward reactions (mainly radical-radical) have no influence on the ignition process.

From the CSP data it is observed that the radicals $O H, H$ and $\mathrm{HO}_{2}$ are produced and consumed at rates much larger than the radical $O$. It means that the production-consumption of these radicals are contained in the dead reaction groups for all times up to ignition. Therefore, the reaction rate of reactions (3) and (5) are limited by the radical pool concentration and the species $\mathrm{H}, \mathrm{OH}$, and $\mathrm{HO}_{2}$ can be assumed to be in steady-state. The kinetic mechanism reduces to

$$
\mathrm{H}_{2}+\mathrm{O}_{2} \stackrel{3+5+14}{\rightarrow} \mathrm{H}_{2} \mathrm{O}+\mathrm{O}
$$

$$
O+O \stackrel{9}{\rightarrow} O_{2}
$$


where the number above the arrow represents the rate of the elementary reaction associated with the global step. From the steady-state assumptions for $H$ and $O H$, the concentration of these radicals are related to that of atomic oxygen as

$$
\begin{gathered}
\frac{C_{H}}{C_{H 2}}=\frac{K_{14}}{\left(K_{1}+\bar{K}_{9}\right)}+\frac{K_{3} C_{O}}{\left(K_{1}+\bar{K}_{9}\right) C_{O 2}}+\frac{K_{5} K_{3}^{1 / 2} C_{H 2}^{1 / 2} C_{O}^{1 / 2}}{\left(K_{1}+\bar{K}_{9}\right) K_{7}^{1 / 2} C_{O 2}^{1}} \\
C_{O H}=\frac{K_{3}^{1 / 2} C_{H 2}^{1 / 2} C_{O}^{1 / 2}}{K_{7}^{1 / 2}}
\end{gathered}
$$

where $\bar{K}_{9}$ corresponds to the equivalent two-body reaction rate of the three body reaction (9). The reaction rate of the two global steps are then given by

$$
\begin{gathered}
w_{I}=K_{14} C_{O 2} C_{H 2}+K_{3} C_{O} C_{H 2}+K_{5} K_{3}^{1 / 2} K_{7}^{-1 / 2} C_{H 2}^{3 / 2} C_{O}^{1 / 2} \\
w_{I I}=\frac{\bar{K}_{9}}{\left(K_{1}+\bar{K}_{9}\right)} w_{I} .
\end{gathered}
$$

For high initial temperatures, the reaction rate of reaction (9) is very small compared reaction (1), that is $K_{1} \gg \bar{K}_{9}$ and then the second global step is very slow and can be neglected in the ignition process in a first approximation. Global step 1 corresponds to a chain branching step with radical $O$ as the chain branching species. We introduce the following nondimensional variables

$$
x=\frac{C_{O}}{\left(C_{H 2}\right)_{0}} ; y=\frac{C_{H}}{\left(C_{O 2}\right)_{0}} ; u=\frac{C_{H 2}}{\left(C_{H 2}\right)_{0}} ; s=\left(K_{3}\right)_{0}\left(C_{H 2}\right)_{0} t
$$

where ( $)_{0}$ is the value of the variable at $t=0$ and $T=T_{O}$. From coupling relationships we obtain

$$
u=1-x ; y=1-2 \phi x .
$$

The evolution equation for the nondimensional concentration of the atomic oxygen can be written as

$$
\begin{gathered}
\frac{d x}{d s}=\frac{K_{3}}{\left(K_{3}\right)_{0}} x(1-x)+\frac{K_{14}}{\left(K_{3}\right)_{0}} \frac{1}{2 \phi}(1-x)(1-2 \phi x) \\
+\frac{K_{5} K_{3}^{1 / 2}}{\left(K_{3}\right)_{0} K_{7}^{1 / 2}}(1-x)^{3 / 2} x^{1 / 2},
\end{gathered}
$$


where $\phi$ corresponds to the equivalence ratio and then

$$
\left(C_{H 2}\right)_{0}=\frac{p}{R T} \frac{2 \phi}{(2 \phi+4.76)} ;\left(C_{O 2}\right)_{0}=\frac{p}{R T} \frac{1}{(2 \phi+4.76)} .
$$

For high initial temperatures and very lean mixtures of hydrogen, the energy release can be neglected in a first approximation. The ignition is then a chain branching process. The ignition criterion used in this analysis is related with the condition for partial equilibrium of one of the shuffle reactions. The election of one or the other brings only very small errors in the ignition delay time. Assuming reactions (7) and (8) reach partial equilibrium then the final nondimensional atomic oxygen concentration is then

$$
x_{f}=\frac{K_{3}}{K_{3}+K_{8}} .
$$

Introducing a normalized nondimensional atomic oxygen concentration, $z=x / x_{f}$, Eq. (13) takes the form

$$
\frac{d z}{d s}=\gamma_{3} z\left(1-x_{f} z\right)+\gamma_{14}\left(1-x_{f} z\right)\left(1-x_{f} \phi z\right)+\gamma_{5}\left(1-x_{f} z\right)^{3 / 2} z^{1 / 2}
$$

where

$$
\gamma_{3}=\frac{K_{3}}{\left(K_{3}\right)_{0}} ; \gamma_{14}=\frac{K_{14}}{\left(K_{3}\right)_{0}} \frac{1}{2 \phi x_{f}} \text { and } \gamma_{5}=\frac{K_{5} K_{3}^{1 / 2}}{\left(K_{3}\right)_{0} K_{7}^{1 / 2} x_{f}^{1 / 2}}
$$

In Eq. (5) $\gamma_{14}$ is very small and $\gamma_{5}$ is small compared with unity. Neglecting the effect of reaction (5), due to the fact that both $\mathrm{COH}$ and $C_{H_{2}}$ are very small for very lean mixtures $(\phi \rightarrow 0)$, Eq. (16) can be integrated in this limit, resulting

$$
s_{i g}=\frac{1}{1+2 \gamma_{14} x_{f}} \operatorname{Ln}\left\{\frac{1+\gamma_{14}}{\gamma_{14}} \frac{1+\gamma_{14} x_{f}}{1-x_{f}\left(1-\gamma_{14}\right)}\right\} .
$$

In physical units, the ignition delay time is given by

$$
t_{i g}=\frac{R T_{0}(2 \phi+4.76)}{2 \phi p K_{3}} s_{i g} \approx \frac{R T_{0}(2 \phi+4.76)}{2 \phi p K_{3}} \operatorname{Ln}\left\{\frac{2 K_{3}^{2} \phi}{K_{14} K_{8}}\right\} .
$$


484

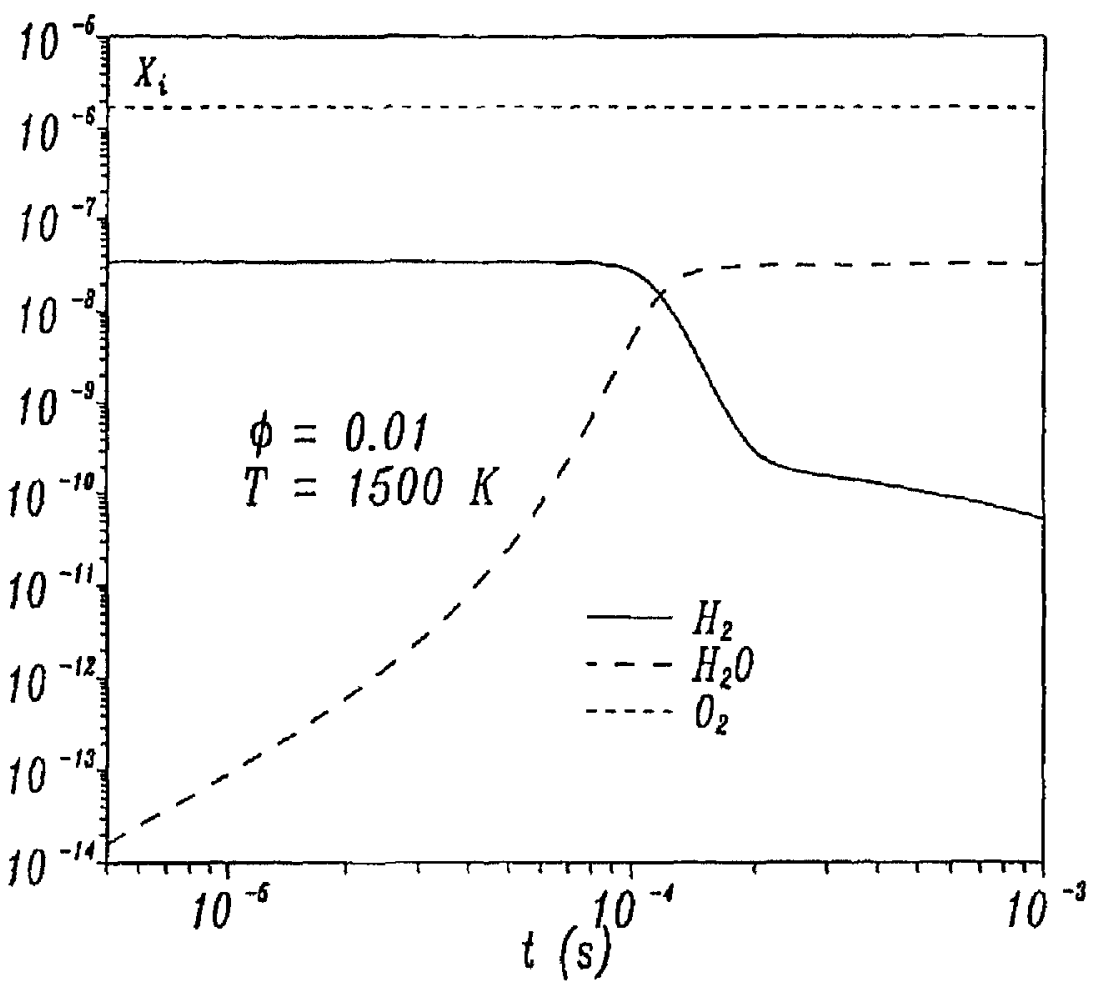

Fig. 1. Main species concentration evolution for an hydrogen/air mixture with $\phi=0.01$ and $T_{0}=1500 \mathrm{~K}$.

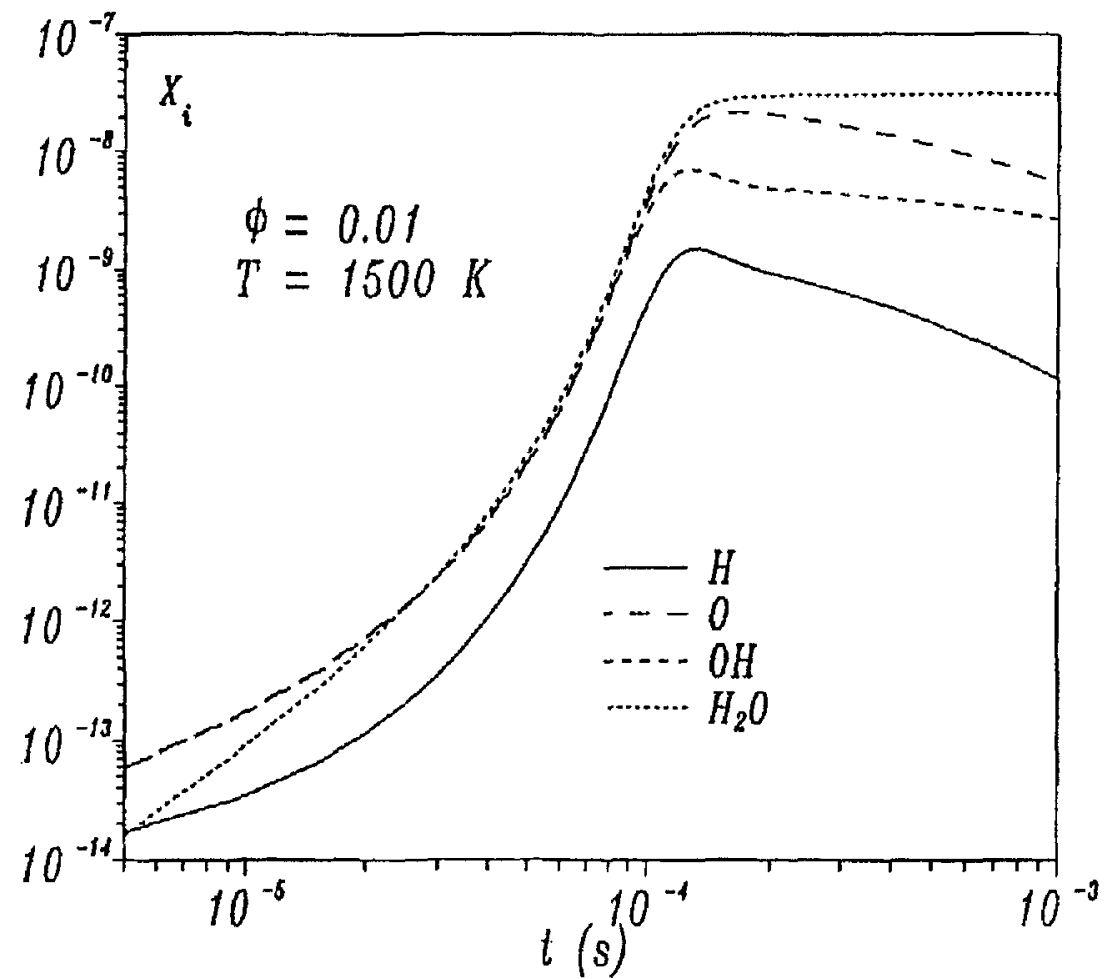

Fig. 2. Products and intermediate species concentration evolution for an hydrogen/air mixture with $\phi=0.01$ and $T_{0}=1500 \mathrm{~K}$. 


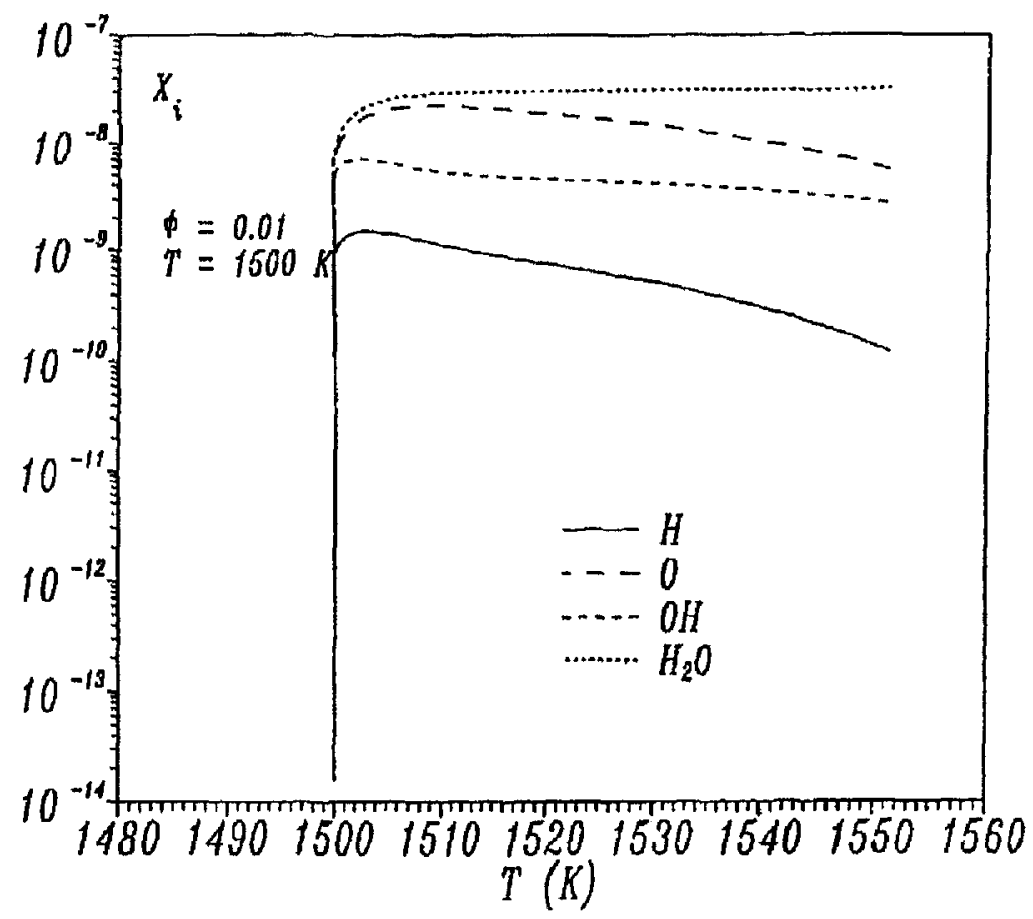

Fig. 3. Phase-plot of product and intermediate species concentration as a function of temperature for an hydrogen/air mixture with $\phi=$ 0.01 and $T_{0}=1500 \mathrm{~K}$.

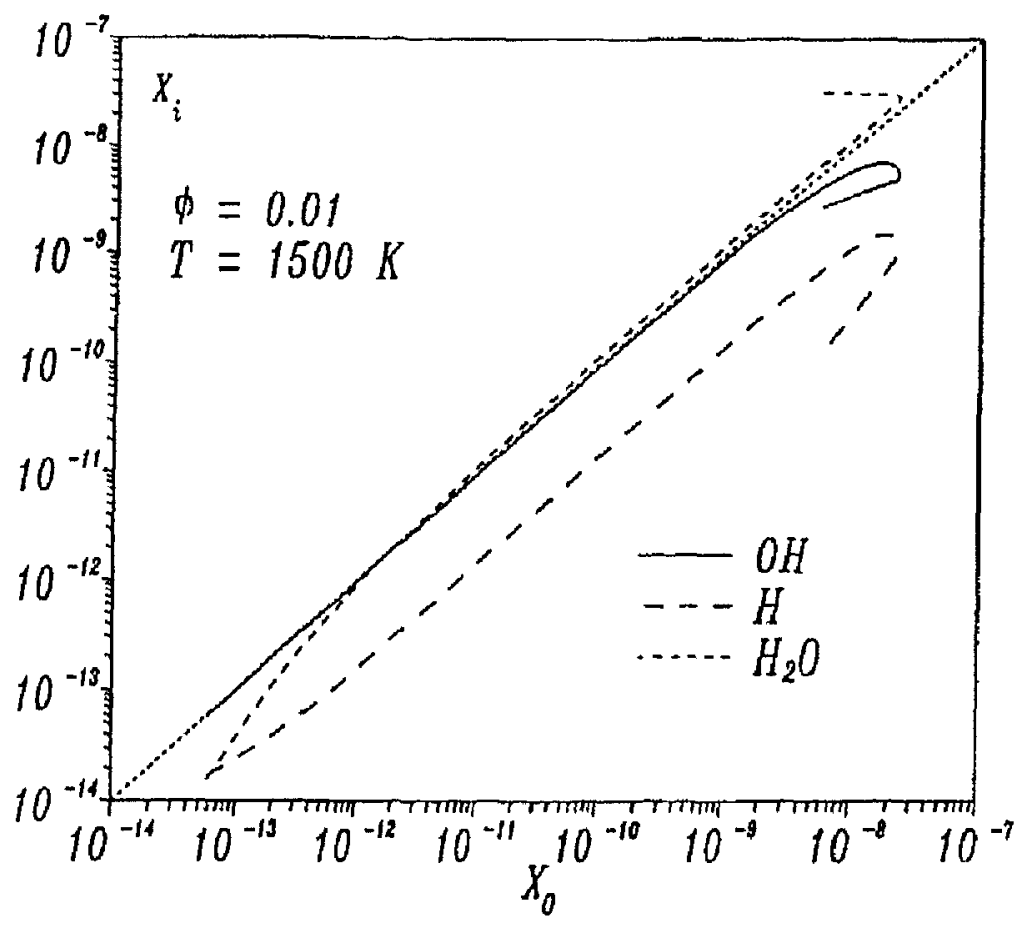

Fig. 4. Phase-plot of product and intermediate species concentration as a function of the $O$ radical concentration for an hydrogen/air mixture with $\phi=0.01$ and $T_{0}=1500 \mathrm{~K}$. 


\begin{tabular}{|c|c|c|c|c|c|c|}
\hline 1,2$)$ & $\mathrm{H}+\mathrm{O}_{2}$ & $=$ & $O H+O$ & $2.0010^{14}$ & 0.0 & 70 \\
\hline 3,4$)$ & $\mathrm{H}_{2}+\mathrm{O}$ & $=$ & $O H+H$ & $5.0610^{04}$ & 2.7 & 6.8 \\
\hline 5,6$)$ & $\mathrm{H}_{2}+\mathrm{OH}$ & $=$ & $\mathrm{H}_{2} \mathrm{O}+\mathrm{H}$ & $1.0010^{08}$ & 1.6 & 3.8 \\
\hline 8$)$ & $O H+O H$ & $=$ & $\mathrm{H}_{2} \mathrm{O}+\mathrm{O}$ & $1.5010^{09}$ & 1.1 & 0. \\
\hline, 10$)$ & $\mathrm{H}+\mathrm{O}_{2}+M$ & $=$ & $\mathrm{HO}_{2}+\mathrm{M}$ & $2.3010^{18}$ & -0.8 & 0.0 \\
\hline 1,12$)$ & $\mathrm{HO}_{2}+\mathrm{H}$ & $=$ & $O H+O H$ & $1.5010^{14}$ & 0.0 & 4.2 \\
\hline ) & $\mathrm{HO}_{2}+\mathrm{H}$ & & $\mathrm{H}_{2}+\mathrm{O}_{2}$ & $2.5010^{13}$ & 0.0 & 6.9 \\
\hline & $\mathrm{HO}_{2}+\mathrm{OH}$ & $=$ & $\mathrm{H}_{2} \mathrm{O}+\mathrm{O}_{2}$ & $.0010^{13}$ & 0.0 & 0.0 \\
\hline & $\mathrm{HO}_{2}+\mathrm{H}$ & $=$ & $\mathrm{H}_{2} \mathrm{O}+\mathrm{O}$ & 3.00 & 0.0 & 7.2 \\
\hline , & $\mathrm{HO}_{2}+\mathrm{O}$ & $=$ & $\mathrm{OH}+\mathrm{O}_{2}$ & $1.8010^{11}$ & 0.0 & -1.7 \\
\hline 0 & $\mathrm{HO}_{2}+\mathrm{HO}_{2}$ & $=$ & $\mathrm{H}_{2} \mathrm{O}_{2}+\mathrm{O}_{2}$ & 2.50 & 0.0 & -5.20 \\
\hline & $O H+O H+M$ & $=$ & $\mathrm{H}_{2} \mathrm{O}_{2}+\mathrm{M}$ & 3.25 & -2.0 & $0.0 c$ \\
\hline . & $\mathrm{H}_{2} \mathrm{O}_{2}+\mathrm{H}$ & $=$ & $\mathrm{H}_{2}+\mathrm{HO}_{2}$ & $1.7010^{10}$ & 0.0 & 15.70 \\
\hline 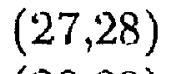 & $\mathrm{H}_{2} \mathrm{O}_{2}+\mathrm{H}$ & $=$ & $\mathrm{H}_{2} \mathrm{O}+\mathrm{OH}$ & $1.0010^{11}$ & 0.0 & 15.00 \\
\hline & $\mathrm{H}_{2} \mathrm{O}_{2}+\mathrm{O}$ & $=$ & $\mathrm{OH}+\mathrm{HO}_{2}$ & $2.8010^{11}$ & 0.0 & 26.8 \\
\hline & $\mathrm{H}_{2} \mathrm{O}_{2}$ & $=$ & $\mathrm{H}_{2} \mathrm{O}+\mathrm{HO}_{2}$ & 5.40 & 0.0 & 4.20 \\
\hline & $H_{2}+M$ & & $H+H+M$ & $6.7610^{16}$ & -1.0 & 436.2 \\
\hline & $H+O H+M$ & $=$ & $\mathrm{H}_{2} \mathrm{O}+\mathrm{M}$ & $2.2010^{20}$ & -2.0 & 0.0 \\
\hline 7 & $O+O+M$ & & $\mathrm{O}_{2}+\mathrm{M}$ & $2.9010^{15}$ & -1.0 & 0.0 \\
\hline
\end{tabular}

Table 1. Mechanism of the $\mathrm{H}_{2} / \mathrm{O}_{2}$ mixtures.

Units: A (cm,mole,s); $\mathrm{E}(\mathrm{KJ} / \mathrm{mole}) ; K=A T^{n} \exp (-E / R T)$ 


\section{Results and Conclusions}

Fig. 1 shows the concentration of the main species as a function of time for a very lean mixture with an equivalence ratio of $\phi=0.01$ and an initial temperature of $T_{0}=1500 \mathrm{~K}$. The molecular oxygen concentration changes very little during the ignition process. Molecular hydrogen disappears almost completely, allowing water vapor concentration to increase. The concentration of active radicals and water vapor as a function of time are shown in Fig. 2 for the same initial conditions. The concentration of atomic hydrogen is always very low, due to the fast reaction (1). The concentration of radicals $O H$ and $O$ increase almost at the same rate, together with that of the water vapor, but $O H$ reaches a maximum (steady-state behavior) before ignition. Fig. 3 shows a phase-plane plot of the concentration of radicals and water vapor as a function of the temperature, for the same initial conditions. We see here that the concentration of all products and intermediate species increase with no heat release up to the ignition condition. The temperature then increases slowly because radical recombination was not considered in the reduced kinetic scheme developed here (no radical- radical reactions). The ignition event is then a typical isothermal process for very lean mixture. Fig. 4 shows the product and intermediate species concentration as a function of the concentration of the main radical $O$. Here again, it is shown how the concentrations of $\mathrm{O}$ and $\mathrm{H}_{2} \mathrm{O}$ increase almost at the same rate up to the ignition point. The steady-state behavior of $O H$ and $H$ is also shown clearly in the figure. Fig. 5 shows a comparison of the radical concentration evolution with time for a stoichiometric and a very lean mixture. In the stoichiometric mixture, the most important radical is the atomic hydrogen with the atomic oxygen following the steady-state behavior. For very lean mixtures the reverse is obtained, with the atomic oxygen as the main radical. Ignition occurs for lower radical concentration. Finally, Fig. 6 shows the ignition delay time for stoichiometric and lean hydrogen/air mixtures computed numerically with full kinetics (solid line) as a function of the equivalence ratio. The asymptotic solution given by Eq. (18) is also shown in this figure, giving very good agreement with the numerical results and following the same trend with the equivalence ratio. The asymptotic relationship obtained using the overall global step

$$
3 \mathrm{H}_{2}+\mathrm{O}_{2} \rightarrow 2 \mathrm{H}_{2} \mathrm{O}+2 \mathrm{H}
$$




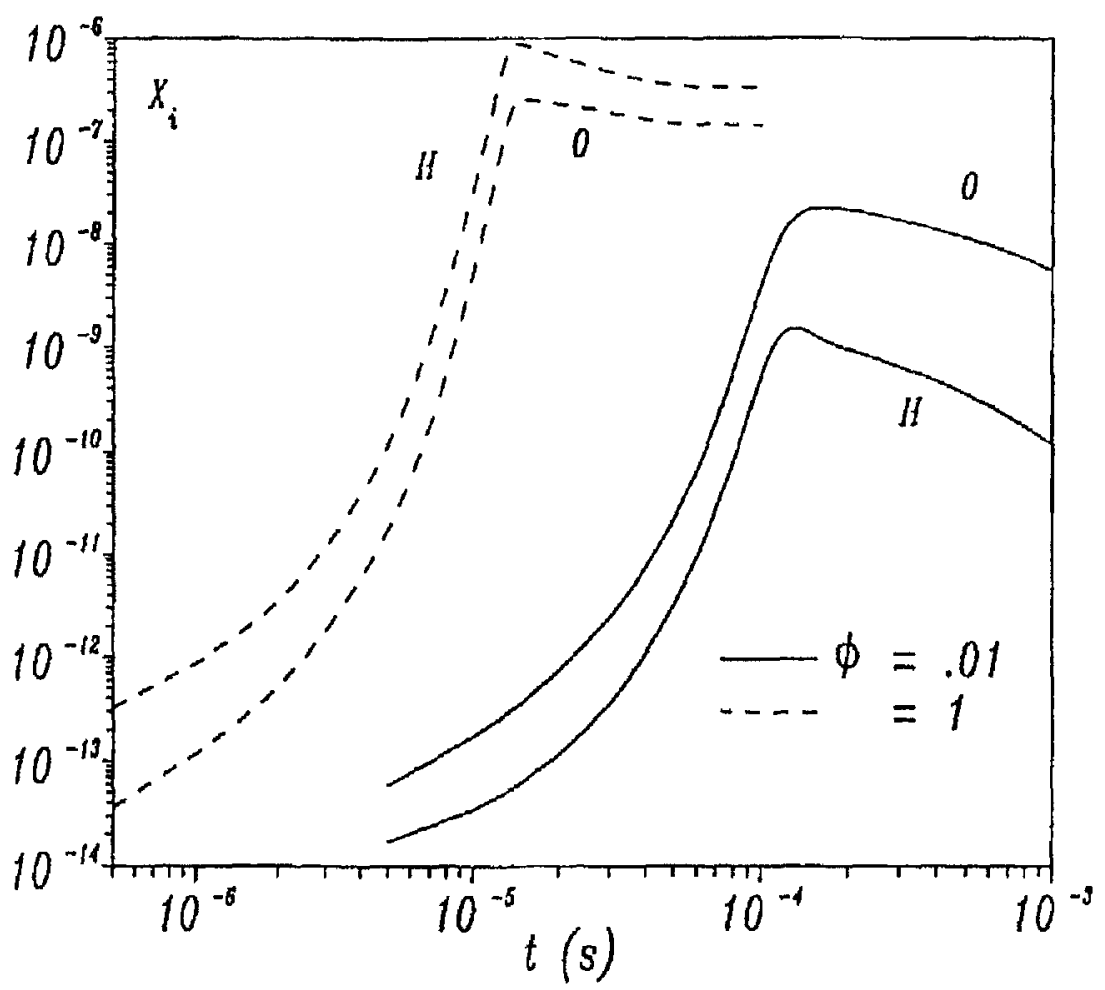

Fig. 5. Radical concentration evolution for two different equivalence ratios and $T_{0}=1500 \mathrm{~K}$.

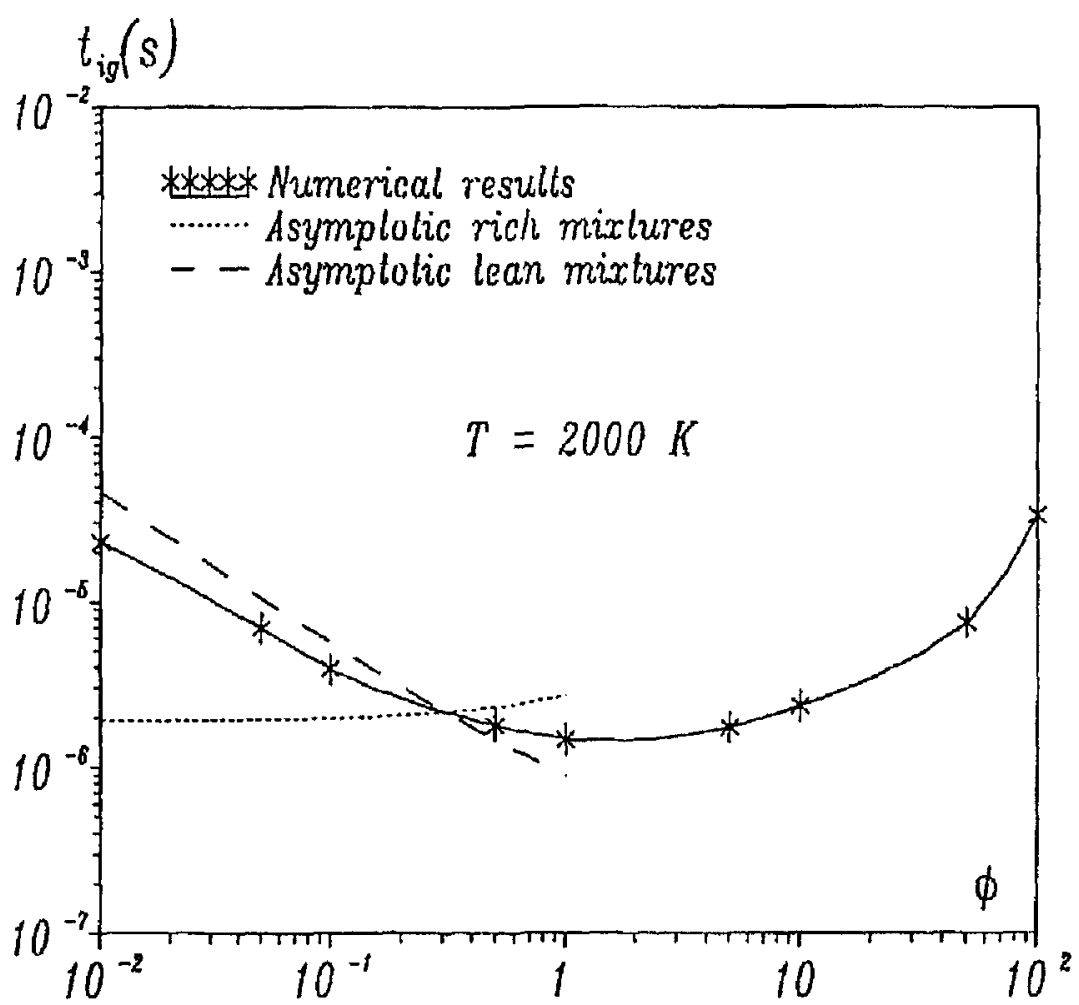

Fig. 6. Numerical and asymptotic solution for the ignition delay time as a function of the equivalence ratio for an initial temperature of $2000 \mathrm{~K}$. 
obtained for stoichiometric and rich mixtures is also plotted. This relationship shows the inverse behavior of the ignition delay time with the equivalence ratio.

The transient analysis leading to the ignition of lean mixtures of hydrogen and oxygen is studied in this paper using both numerical analysis based in Computational Singular Perturbation (CSP) and asymptotic analytical methods. The reduced kinetic mechanism is obtained after solving the evolution equations and evaluating the CSP data. For lean mixtures with high initial temperatures, fuel consumption is very important and the limiting reaction switches from reaction (1) for stoichiometric and rich mixtures to reaction (3) for lean mixtures due to the low concentration of molecular hydrogen. A simple formula for the ignition delay time is obtained in this case showing a very good agreement with numerical results with full kinetics.

\section{Acknowledgements}

César Treviño thanks the DGICYT of Spain for supporting a sabbatical leave in Madrid.

\section{References}

Baulch, D. L., Drysdale, D. D., Horne, D. G., and Lloyd, A. C., 1972. "Evaluated kinetic data for high temperature reactions, Vol. 1: Homogeneous gas phase reactions of the $\mathrm{H}_{2}-\mathrm{O}_{2}$ system," Butherworths, London.

Brokaw, R. S., 1965. "Analytic solutions to the ignition kinetics of the hydrogen-oxygen reaction," 10th (Symposium) International on Combustion, The Combustion Institute, pp. 269-278.

Dixon-Lewis, G. and Williams, D. J., 1977. Comprehensive Chemical Kinetics, Vol. 17: The Oxidation of Hydrogen and Carbon Monoxide, Elsevier, Oxford, C. H. Bamford and C. F. H. Tipper (eds.).

Gardiner, W. C., Wakefield, C. B., and Walker, B. F., 1981. Shock Waves in Chemistry and Chemical Technology, Marcel Dekker, New York, A. Lifshitz (ed.). 
Kailasaneth, K., Oran, E. S., Boris, J. P., and Young, T. R., 1982. "Numerical methods in laminar flame propagation," Vieweg, Braunschweig, p. 152.

Lam, S. H. and Croussis, D. A., 1989. "Understanding complex chemical kinetics with computational singular perturbation," XXII Int. Symposium on Combustion, The Combustion Institute, in press.

Maas, U. and Warnatz, J., 1989. "Ignition processes in hydrogenoxygen mixtures," Combustion and Flame, in press.

Peters, N., 1985. "Numerical and asymptotic analysis of systematically reduced reaction schemes for hydrocarbon flames," Lecture Notes in Physics 241, Glowinski et al. (eds.), Springer, New York, pp. 90-109.

Treviño, C., 1990. "Ignition phenomena in $\mathrm{H}_{2} / \mathrm{O}_{2}$ mixtures," Progress in Astronautics and Aeronautics 131, p. 19.

Warnatz, J., 1984. "Rate coefficients in the C/H/O system," Combustion Chemistry, W. C. Gardiner (ed.), Springer, New York, pp. 197-360.

Wiriyawit, S. and Dabora, E. K., 1984. "Modeling the chemical effects of plasma ignition in one-dimensional chamber," 20th Symposium (International) on Combustion, The Combustion Institute, pp. 179-186. 